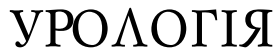

doi: $10.35339 / \mathrm{ekm} .2019 .01 .12$

УДК 616.71-008.82:577.118:616.61-78

\section{Т.Л. Валковская}

Харьковский национальный медицинский университет Областной медццинский клинический центр урологии и нефрологии им. В.И. Шаповала, г. Харьков

\section{ВЗАИМОСВЯЗЬ СОСУДИСТОЙ КАЛЬЦИФИКАЦИИ И КОНЦЕНТРАЦИИ ОСТЕОПОНТИНА В ПЛАЗМЕ КРОВИ У ПАЦИЕНТОВ НА ЗАМЕСТИТЕЛЬНОЙ ПОЧЕЧНОЙ ТЕРАПИИ МЕТОДОМ ПЕРИТОНЕАЛЬНОГО ДИАЛИЗА}

Проведено изучение частоты кальцификации брюшного отдела аорты и роли плазменной фракции остеопонтина в её развитии, а также взаимосвязи между степенью нарушения фосфорно-кальциевого обмена у пациентов с хронической болезнью почек 5-й Д стадии на перитонеальном диализе. Выявлено, что кальцификация брюшного отдела аорты встречается у 73,3 \% пациентов данной группы. Предикторами развития сосудистой кальцификации является возраст больных и длительность диализной терапии. С прогрессированием степени сосудистой кальцификации наблюдается ухудшение показателей костно-минерального обмена в виде статистически достоверного увеличения уровней сывороточного фосфора, фосфорно-кальциевого произведения и паратиреоидного гормона. Концентрация остеопонтина в плазме крови коррелирует со степенью тяжести кальцификации брюшной аорты и может быть маркером сосудистой кальцификации у диализных пациентов.

Ключевые слова: хроническая болезнь почек, перитонеальный диализ, костно-минеральный обмен, остеопонтин, сосудистая кальиификаиия.

\section{Введение}

Риск летальности от сердечно-сосудистых заболеваний у больных с 5-й Д стадией хронической болезни почек (ХБП) превышает таковой в общей популяции примерно в 330 раз [1]. При этом степень сосудистой кальцификации является одной из основных причин и независимых предикторов неблагоприятного исхода. Показана чёткая взаимосвязь между нарушением минерального обмена, потерей минеральной плотности кости и скоростью прогрессирования сосудистой кальцификации (СК) как в общей популяции, так и больных с ХБП [2]. СК - это патологический процесс, характеризующийся утолщением и потерей эластичности мышечной артериальной стенки в результате отложения солей кальция и фосфора в медиальной и (или) интимальной оболочке сосудов. Кальцификация сосудов часто ассоциируется со старением, но при терминальной уремии этот процесс приобретает злокачественный характер. Исследователями последних лет показано, что при ХБП развитие СК ассоциировано с гиперкальциемией, гиперфосфатемией, адинамической болезнью кости и вторичным гиперпаратиреозом [3]. При этом изучение патогенетических механизмов СК и поиск её новых маркеров продолжается. Установлено, что костные клетки принимают непосредственное участие в патологических изменениях функции и структуры сосудов вследствие эктопического остеогенеза с участием специфических костных протеинов, экспрессирующихся в стенке сосудов. В связи с этим представляет интерес остеопонтин (ОП), костный сиалопротеин, главный неколлагеновый матриксный белок костей, который экспрессируется в минерализованных тканях. Негативная роль ОП в кальцификации медии была описана у паци-

(C) Т.Л. Валковская, 2019 
ентов с терминальной почечной дисфункцией, находящихся на гемодиализе (ГД) [4]. В экспериментальных условиях S. SakurabayashiKitade и соавторы показали, что содержание ОП в интиме и медии артерий подвергается up-regulation после воздействия альдостерона и ангиотензина II. Авторы исследования полагают, что ОП обуславливает пролиферацию гладкомышечных клеток и деградацию эластической мембраны медии артерий, что рассматривается как одна из начальных стадий васкулярного ремоделирования [5].

Таким образом, ОП является перспективным для изучения маркером, который принимает участие в процессах сосудистой перестройки, а его вклад в развитие сосудистого кальциноза при ХБП достаточно неодназначен, до настоящего времени окончательно не установлен и продолжает изучаться.

Цель исследования - определение частоты кальцификации брюшного отдела аорты (КБА) и изучение роли плазменной фракции ОП в её развитии, а также взаимосвязи между степенью нарушения фосфорно-кальциевого обмена, интенсивностью процессов СК и уровнем ОП у больных на заместительной почечной терапии (ЗПТ) методом перитонеального диализа (ПД).

\section{Материал и методы}

Исследование проводилось в отделении нефрологии и перитонеального диализа Областного медицинского клинического центра урологии и нефрологии им. В.И. Шаповала. Заместительную терапию методом постоянного амбулаторного перитонеального диализа (ПАПД) в исследуемой группе получали 45 пациентов (33 мужчины и 13 женщин) в возрасте от 19 до 71 года, средний возраст - $(45 \pm 10)$ лет. Критерии исключения: инфаркт миокарда или острое нарушение мозгового кровообращения в анамнезе, стабильная стенокардия напряжения, сердечная недостаточность 3-4 функциональные классы (ФК), острые инфекционные процессы какой-либо этиологии на протяжении последних 3 месяцев, онкологические заболевания. Этиология ХБП представлена: хроническим гломерулонефритом - $65,8 \%$; хроническим пиелонефритом $-2,6 \%$; поликистозом почек - $15 \%$; диабетической нефропатией - $12,6 \%$; гипертонической болезнью - $1,1 \%$. Суммарный $\mathrm{Kt} / \mathrm{v}-$ $2.31 \pm 0.46$. Длительность ЗПТ от 13 месяцев до 9 лет $[(5.0 \pm 0.5)$ лет]. ПАПД проводился в режиме 4-5 обменов за сутки с интервалом в 4 6 часов. Больные использовали диализные растворы «дианил» с содержанием $\mathrm{Ca}++$
1,25 ммоль/л и «экстранил» с содержанием Са+ + 1,75 ммоль/л.

Всем пациентам проводилось стандартное клинико-лабораторное обследование. Оценивался уровень кальция (Ca), фосфора (Р) сыворотки крови, кальциево-фосфорное произведение $(\mathrm{Ca}$ Р), щелочной фосфатазы (ЩФ). Методом иммуноферментного анализа в условиях лаборатории ОМКЦУН им. В.И. Шаповала определяли уровень паратиреоидного гормона (ПТГ), ОП на основе набора Human Osteopontin Platinum ELISA в соответствии с протоколами производителей.

Для выявления СК использовали различные диагностические методы - неинвазивные (ультразвуковое исследование сосудов и клапанов сердца, рентгенография) и инвазивные (коронаро- и артериография). «Золотым» стандартом для выявления СК считают компьютерную томографию с оценкой по шкале Agatson, однако такого рода обследование диализных пациентов могут позволить себе только клиники с высоким уровнем оснащённости, поскольку этот вид диагностики остаётся дорогостоящим. Методика оценки кальцификации брюшного отдела аорты (КБА), определённой с помощью латерального абдоминального снимка, предложенная L. Kauppila et. al. (1997), может выступать реальной альтернативой компьютерной томографии. Учитывая вышеизложенное, больным, включённым в исследование, было выполнено рентгенологическое исследование - обзорная рентгенография брюшной полости в боковой проекции в области L1 - L4 с зоной захвата не менее 4 см кпереди от позвоночного столба для оценки КБА. Проводили оценку степени тяжести кальцификации на уровне каждого отдельного сегмента (с первого по четвёртый поясничный позвонок), передней и задней стенки аорты, а также суммировался общий балл кальцификации (максимальный суммарный балл кальцификации был равен 24). Выраженность процесса оценивалась от 0 до 3 баллов.

\section{Результаты}

КБА в исследуемой нами группе встречалась с частотой $73,3 \%$. Выраженность КБА варьировалась от 1 до 23 баллов. Средний балл кальцификации составил 7,23 $\pm 5,40$. Для проведения анализа различий по уровню изучаемого биологического маркера в плазме крови - ОП, нарушений фосфорно-кальциевого обмена у пациентов с различной степенью сосудистой кальцификации, все участники исследования были разделены на 4 груп- 
Таблиияа 1. Шкала кальцификаичи по баллам

\begin{tabular}{|c|l|}
\hline Баллы & \multicolumn{1}{|c|}{ Характеристика изменений } \\
\hline 0 & Кальцинаты отсутствуют \\
\hline 1 & $\begin{array}{l}\text { Мелкие отдельные кальцинаты, занимающие менее 1/3 протяжённости стенки аорты } \\
\text { на уровне отдельного позвонка }\end{array}$ \\
\hline 2 & $1 / 3-2 / 3$ стенки кальцинированы \\
\hline 3 & $>2 / 3$ протяжённости стенки аорты повреждены кальцификацией \\
\hline
\end{tabular}

пы (табл. 2). В 1-ю группу вошли пациенты с ХБП 5-й Д стадии без КБА (n=18), во 2-ю пациенты с выраженностью КБА (от 1 до 4) баллов $(\mathrm{n}=12)$, в 3-ю - (от 5 до 15) баллов $(\mathrm{n}=6)$ и 4-ю группу с КБА (от 16 до 24) баллов $(\mathrm{n}=9)$.
КБА был 4,64 4,60 , а среди пациентов с уровнем Р выше 1,77 ммоль/л - 6,78 $\pm 5,26$. При изучении фосфорно-кальциевой производной наблюдалась тенденция, аналогичная фосфатемии: повышение показателя СагР по мере нарастания выраженности КБА.

Таблица 2. Показатели кальций-фосфорного обмена в зависимости от степени выраженности КБА

\begin{tabular}{|c|c|c|c|c|c|}
\hline Показатель & $\begin{array}{c}\text { 1-я группа } \\
\text { без КБА } \\
(n=18)\end{array}$ & $\begin{array}{c}\text { 2-я группа } \\
\text { КБА } \\
(1-4 \text { балла) } \\
(n=12)\end{array}$ & $\mid \begin{array}{c}\text { 3-я группа } \\
\text { КБА } \\
\left(\begin{array}{c}(5-15 \text { баллов }) \\
(n=6)\end{array}\right.\end{array}$ & \begin{tabular}{|c} 
4-я группа \\
КБА \\
$(16-23$ балла) \\
$(n=9)$
\end{tabular} & $p$ \\
\hline Возраст, лет & $42,1 \pm 9,7$ & $46,9 \pm 7,7$ & $48,9 \pm 11,3$ & $52,3 \pm 11,6$ & $p \leq 0,001$ \\
\hline \begin{tabular}{|l|} 
Продолжительность \\
диализной терапии, мес
\end{tabular} & $54 \pm 7$ & $59 \pm 4$ & $64 \pm 9$ & $68 \pm 7$ & $p \leq 0,001$ \\
\hline Р, ммоль/л & $1,7 \pm 0,5$ & $2,1 \pm 0,8$ & $2,4 \pm 0,4$ & $2,5 \pm 0,6$ & $p \leq 0,05$ \\
\hline Са, ммоль/л & $2,1 \pm 0,1$ & $2,2 \pm 0,4$ & $2,5 \pm 0,3$ & $2,7 \pm 0,2$ & $p \geq 0,05$ \\
\hline 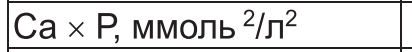 & $4,30 \pm 0,99$ & $5,20 \pm 0,78$ & $5,96 \pm 1,01$ & $7,15 \pm 1,17$ & $p \leq 0,05$ \\
\hline ПТГ пг/мл & $268,0 \pm 21,7$ & $497,0 \pm 33,7$ & $524,00 \pm 16,88$ & $951,0 \pm 92,6$ & $p \leq 0,05$ \\
\hline ОП нг/мл & $89,0 \pm 24,4$ & $119,7 \pm 18,4$ & $254,00 \pm 29,3$ & $289,0 \pm 50,3$ & $p \leq 0,05$ \\
\hline
\end{tabular}

При сравнении клинических и лабораторных параметров диализных больных нами не было выявлено связи КБА с нозологией первичного заболевания и полом. Получена прямая зависимость выраженности КБА от возраста - с увеличением возраста пациентов росла выраженность КБА (pJ0,001). С помощью корреляционного анализа было обнаружено, что более выраженный КБА присутствовал у пациентов с большей длительностью диализной терапии (pJ0,001).

Исследуя особенности кальциево-фосфорного гомеостаза у пациентов, получающих ПАПД, было выявлено ухудшение их показателей с прогрессированием СК. Гиперфосфатемия усугублялась по мере нарастания выраженности КБА и достигала максимальных значений у пациентов 4-й группы. Так, уровень сывороточного фосфата (Р) в этой группе больных статистически достоверно превышал аналогичный показатель в 1-й и 2-й группах в 1,47 и 1,41 раза соответственно $(\mathrm{P} \leq 0,05)$. Среди пациентов, Р крови которых был выше 1,77 ммоль/л, имеется тенденция к увеличению степени индекса КБА. Так, при показателях Р ниже 1,77 ммоль/л средний балл
Взаимосвязь между уровнем кальция $(\mathrm{Ca})$ пациентов и индексом КБА была статистически малозначимой. Однако у пациентов с Са ниже 2,5 ммоль/л средний индекс КБА составил 6,18 4,60 , при показателях Са выше 2,5 ммоль/л индекс КБА был 8,76 $\pm 5,30$.

Уровень ПТГ у пациентов 4-й группы (кальцификация 16-24 балла) имел тенденцию к более высоким значениям $(640,07 \pm 367,11)$ и был выше, чем во 2-й и 1-й группах в 2,08 и 3,54 раза соответственно $(\mathrm{p} \leq 0,05)$.

Анализ различий, в уровне изучаемого биологического маркера в плазме крови у пациентов с различной степенью поражения брюшного отдела аорты показал, что у больных 4-й группы ОП оказался достоверно выше в 2,41 и 3,25 раза, чем у пациентов 2 -й и 1 -й групп соответственно $(\mathrm{p} \leq 0,05)$.

\section{Обсуждение}

Сосудистая кальцификация встречается значительно чаще у пациентов с ХБП, чем в общей популяции. По данным, полученным M. Kalpakian и соавт. [6], распространённость кальцификации коронарных артерий пациентов с ХБП в додиализный период составила $40 \%$ по сравнению с 5-13 \% в общей популяции, 
при недавно начатом диализе 64 \% и при длительном применении диализа 83 \%. В связи с тем, что ведущей причиной летальных исходов среди пациентов, получающих заместительную почечную терапию, является кардиоваскулярная патология, во многом обусловленная внеоссальной кальцификацией, крайне важно раннее выявление и её количественная оценка. Брюшная аорта является одной из наиболее чувствительных сосудистых областей, причём возможна оценка степени кальциноза с помощью простого рентгенологического метода. В нашем исследовании КБА был обнаружен у 73,3 \% больных. По данным различных авторов, к инициации процесса кальцификации и ускоренному его развитию ведут различные причины. Среди наших пациентов получена прямая зависимость выраженности КБА от возраста $(\mathrm{p} \leq 0,001)$, что отмечено и в ряде зарубежных исследований [7]. В общей популяции возраст также является предиктором сосудистой кальцификации. У больных, получающих диализную терапию, этот процесс возникает на 10-20 лет раньше, чем в общей популяции и протекает ускоренно. Корреляции КБА с нозологической формой заболевания почек и полом не было, что согласуется с результатами Fernandes-Reyes и соавт. [8]. Длительность диализного лечения по нашим сведениям оказалась значимым фактором, связанным с выраженностью КБА $(\mathrm{p} \leq 0,001)$ и обусловлено, очевидно, длительной экспозицией факторов риска сердечно-сосудистой патологии у данной категории пациентов, что подтверждают данные ряда исследований [9-10].

Проведённый межгрупповой анализ в обследованной группе показал, что при нарастании выраженности КБА у пациентов были более выражены нарушения фосфорно-кальциевого обмена (высокий уровень Р и произведение $\mathrm{Ca} \times \mathrm{P})$, явления гиперпаратиреоза. Гиперпаратиреоз, как было показано в ряде работ, способствует прогрессированию кальциноза аорты и эктопической кальцификации $[3,8]$. В нашей работе выявлена прямая зависимость между сывороточной концентрацией ПТГ и тяжестью КБА. Известно, что при этом состоянии ускоряется ремоделирование костей, усиливается резорбция из них Са и Р, что ведёт к повышению их концентрации в сыворотке крови и способствует кальцификации сосудов и мягких тканей.

Результаты настоящего исследования продемонстрировали различия в концентрации изучаемого биомаркера - ОП в зависимости от степени КБА. Пациенты с уровнем кальцификации 16-24 балла имели тенденцию к более высоким значениям ОП в крови. Обсуждая представленные данные, следует обратить внимание и на ряд экспериментальных и клинических исследований, доказавших важную роль ОП в процессах регуляции кальцификации артериальной стенки. Так, установлена ассоциация между содержанием ОП, с одной стороны, и жёсткостью сосудистой стенки, выраженностью кальцификации атеромы и стабильностью покрышки атеросклеротической бляшки - с другой [4]. Концентрация ОП позитивно коррелирует с риском развития артериальной окклюзии и тромбоза [11]. В ходе экспериментальных исследований доказано отсутствие ОП в «здоровых» сосудах, однако он в изобилии обнаруживается в кальцифицированных артериях и экспрессируется после баллонного повреждения артерии.

Таким образом, выявленная положительная корреляционная связь между плазменной фракцией ОП и степенью КБА может свидетельствовать о том, что этот протеин является маркером сосудистой кальцификации у диализных пациентов.

\section{Выводы}

1. Распространенность сосудистой кальцификации на заместительной почечной терапии методом перитонеального диализа по данным рентгенографии брюшного отдела аорты составила 73,3\%.

2. Предикторами развития сосудистой кальцификации является возраст больных и длительность диализной терапии.

3. С прогрессированием степени СК наблюдается ухудшение показателей костноминерального обмена в виде статистически достоверного увеличения уровней сывороточного фосфора, фосфорно-кальциевого произведения и ПТГ.

4. Концентрация ОП в плазме крови коррелирует со степенью тяжести КБА и может быть маркером сосудистой кальцификации у диализных пациентов.

5. Визуализирующее исследование (рентгенография брюшного отдела аорты) представляет кумулятивный результат длительной предшествовавшей экспозиции факторов риска. Биохимические маркеры (ОП) оценивают риск кальцификации, которому подвержен данный пациент в момент исследования, поэтому комплексный подход диагностических мероприятий у данной категории пациентов позволяет индивидуализировать лечебный процесс. 


\section{References}

1. Di Lullo L., House A., Gorini A., Santoboni A., Russo D., Ronco C. (2015). Chronic kidney disease and cardiovascular complications. Heart. Fail. Rev, May, № 20 (3), pp. 259-272.

2. Goodman W.G., London G., Amann K. et al. (2004). Vascular calcification in chronic kidney disease. Am. J. Kidney. Dis., № 43, pp. 572-579.

3. Giachelli C. (2004). Vascular calcification mechanisms. J. Am. Soc. Nephrol., № 15, pp. 2959 2964.

4. Barreto D.V., Lenglet A., Liabeuf S. et al. (2011). Prognostic implication of plasma osteopontin levels in patients with chronic kidney disease. Nephron. Clin. Pract., № 117 (4), pp. 363-372.

5. Sakurabayashi-Kitade S., Aoka Y., Nagashima H. et al. (2009). Aldosterone blockade by Spironolactone improves the hypertensive vascular hypertrophy and remodeling in angiotensin II overproducing transgenic mice. Atherosclerosis, № 206 (1), pp. 54-60.

6. Kalpakian M.A., Mehrotra R. (2007). Vascular calcification and disordered mineral metabolism in dialysis patients. Seminars in dialysis, № 20 (2), pp. 139-143.

7. Demirci M., Ozkahya M., Asci G. et al. (2009). The influence of dialysate calcium on progression of arterial stiffness in peritoneal dialysis patients. Perit. Dial. Int., № 29 (20), pp. 15-17.

8. Fernandez-Reyes M.J., Auxiliadora Bajo M., Robles P. et al. (1995). Mitral annular calcification in CAPD patients with a low degree of hyperparathyroidism. An analysis of other possible risk factors. Nephrol. Dial. Transplant., № 10 (11), pp. 2090-2095.

9. Niu Q., Zhao H., Wu B. et al. (2019). Study on the Prevalence of Vascular Calcification in Different Types of Arteries and Influencing Factors in Maintenance Peritoneal Dialysis Patients. Blood. Purif., № 30, pp. 1-9.

10. Nitta K., Hanafusa N., Okazaki M., Komatsu M., Kawaguchi H., Tsuchiya K. (2018). Association Between Risk Factors Including Bone-Derived Biomarkers and Aortic Arch Calcification in Maintenance Hemodialysis Patients. Kidney. Blood. Press. Res., № 43 (5), pp. 1554-1562.

11. Cho H.J., Cho H.J., Kim H.S. (2009). Osteopontin: a multifunctional protein at the crossroads of inflammation, atherosclerosis, and vascular calcification. Curr. Atheroscler. Rep., № 11 (3), pp. 206-213.

\section{Т.Л. Валковська}

\section{ВЗАСМОЗВ'ЯЗОК СУДИННОЇ КАЛЬЦИФІКАЦІЇ ТА КОНЦЕНТРАЦЇ ОСТЕОПОНТИНУ В ПЛАЗМІ КРОВІ У ПАЦІЕНТІВ НА ЗАМІСНІЙ НИРКОВІЙ ТЕРАПІЇ МЕТОДОМ ПЕРИТОНЕАЛЬНОГО ДІАЛІЗУ}

Проведено вивчення частоти кальцифікації черевного відділу аорти та ролі плазмової фракції остеопонтину в ії розвитку, а також взаємозв'язку між ступенем порушення фосфорно-кальцієвого обміну у пацієнтів з хронічною хворобою нирок 5-ї Д стадії на перитонеальному діалізі. Виявлено, що кальцифікація черевного відділу аорти зустрічається у 73,3 \% пацієнтів цієї групи. Предикторами розвитку судинної кальцифікації $€$ вік хворих і тривалість діалізної терапії. 3 прогресуванням ступеня судинної кальцифікації спостерігається погіршення показників кістково-мінерального обміну у вигляді статистично достовірного збільшення рівнів сироваткового фосфору, фосфорно-кальцієвого добутку і паратиреоїдного гормону. Концентрація остеопонтину в плазмі крові корелює зі ступенем тяжкості кальцифікації черевної аорти і може бути маркером судинної кальцифікації в діалізних пацієнтів.

Ключові слова: хронічна хвороба нирок, перитонеальний діаліз, кістково-мінеральний обмін, остеопонтин, судинна кальцифікація.

\section{T.L. Valkovskaya}

\section{ASSOCIATION OF VASCULAR CALCIFICATION AND OSTEOPONTIN CONCENTRATION IN BLOOD PLASMA IN PATIENTS ON RENAL REPLACEMENT THERAPY BY PERITONEAL DIALYSIS}

The study of the frequency of calcification of the abdominal aorta and the role of the plasma fraction of osteopontin in its development and the relationship between the degree of violation of phosphoruscalcium metabolism in patients with chronic kidney disease stage 5 on peritoneal dialysis. It was found that calcification of the abdominal aorta occurs in $73.3 \%$ of patients in this group. Predictors of vascular calcification is the age of patients and the duration of dialysis. With the progression of the degree of vascular calcification observed deterioration of bone mineral metabolism in the form of statistically significant 
increase in serum phosphorus, phosphorus-calcium product and parathyroid hormone. The plasma concentration of osteopontin correlates with the severity of abdominal aortic calcification and may be a marker of vascular calcification in dialysis patients.

Keywords: chronic kidney disease, peritoneal dialysis, bone mineral metabolism, osteopontin, vascular calcification.

Надійила до редакиії 19.02.2019

\section{Контактна інформація}

Валковська Тетяна Леонідівна - аспірант кафедри урології, нефрології та андрології імені професора А.Г. Подрєза Харківського національного медичного університету. Лікар-нефролог відділення нефрології та перитонеального діалізу КНП ХОР «Обласний медичний клінічний центр урології і нефрології ім. В.І. Шаповала».

Адреса: Україна, 61037, м. Харків, пр. Московський, 195.

Тел.:+380990158588.

E-mail:t.valkovskaya@ukr.net.

ORCID: 0000-0001-7067-6856. 